\title{
Assistolia em paciente submetida à raquianestesia
}

- Jurandy B. Silva

- Adecir G. Neubaver

- André $\bigcirc$. Cenci

Dante Ranieri Júnior

\section{CET-SBA do Serviço de Anestesiologia Itajai, Itajai, Santa Catarina}

INTRLDUCॄÃa

A raquianestesia é um procedimento utilizado com freqüência para cirurgias do abdome inferior. Apesar da sua aparente simplicidade, é dotada de riscos, dentre eles, a parada cardíaca, numa incidência de $0,07 \%$. Relatamos a seguir o caso de uma paciente que evoluiu com assistolia após ter sido submetida à raquianestesia.

\section{RELATD DO CASD}

Paciente do sexo feminino, 50 anos, estado físico P1 (antigo ASA I), com indicação de histerectomia abdominal por miomatose uterina. Hemodinamicamente encontrava-se estável, exame cardiopulmonar e laboratorial sem alterações, IMC $36,3 \mathrm{~kg} / \mathrm{m}^{2}$. A paciente foi monitorizada com PANI, cardioscópio e $\mathrm{SpO}_{2}$. Venóclise com cateter $18 \mathrm{G}$ em MSD e sedada com midazolam $1 \mathrm{mg}$. Foi proposta uma raquianestesia com bupivacaína hiperbárica $0,5 \% 20 \mathrm{mg}$, sufentanil, $3 \mathrm{mcg}$ e morfina $50 \mathrm{mcg}$, com a paciente sentada, no interespaço L2-L3 e agulha tipo Quincke 26 numa velocidade de $1 \mathrm{ml} / 3 \mathrm{~s}$. Em seguida foi colocada em cefalodeclive e, após 3 minutos da injeção, foi testado o nível térmico do bloqueio, que já se encontrava em T2-T3. Decidiu-se pela atropinização precoce $(0,5 \mathrm{mg})$ e, enquanto se preparava a droga, a paciente evoluiu com bradicardia severa seguida de traçado de ECG isoelétrico, ausência de curva de pletismografia e de pulso carotídeo. Com a paciente em cefalodeclive, iniciaram-se as manobras de ressuscitação. Após 30 segundos de MCE, já se observava a presença de pulso carotídeo e retorno do ritmo sinusal, bem como exame neurológico normal. $\mathrm{O}$ ato cirúrgico, a partir de então, transcorreu normalmente e a paciente recebeu alta da SRPA após $3 \mathrm{~h}$ do bloqueio.

DISடบSรÃロ

A arritmia mais freqüente relacionada à raquianestesia é a bradicardia, entretanto, neste caso, a mesma foi tão severa, que evoluiu para assistolia. Relacionamos tal fato não só ao bloqueio das fibras cardioaceleradoras, mas também ao desencadeamento de reflexos cardíacos, como o Bezold Jarish. Em pacientes com instalação alta de bloqueio (acima de T4), a atropinização precoce se mostra uma alternativa adequada.

\section{REFERÊNCIAS}

1. Pollard JB. Cardiac arrest during spinal anesthesia: conmon mechanisms and strategies for prevention. Anesth Analg. 2001;92:252-6.

2. Auroy Y, Narchi P, Messiah A, et al. Serious complications related to regional anesthesia. Anesth. 1997;87:479-86.

\section{Endereço para correspondência:}

Jurandy B. Silva

Avenida Marcos Konder, 1.111 - Centro

Itajaí (SC) - CEP 88301-303 